\title{
Embracing uncertainty and ignorance in medical practice
}

Medical practice is changing with everincreasing speed. It can be said, with certain caution, that up to the Second World War physicians practiced medicine with very few resources and limited knowledge. However, and paradoxically, the years elapsed between the mid-19th century and that time were referred to as "the golden age of medical practice". To a great extent, this was because of a change in physicians' attitudes, who started raising the value of office visits with empathy, unhurriedness and a considerable level of caution with limited therapeutic measures. Little was done regarding the natural course of disease, except accompanying patients and their families, the greatest gift of our profession. Thus, physicians gained respect and gradually earned people's trust, achieving huge recognition from society. It is worth noting that until the introduction of penicillin (early 1940s), there was no solid evidence on a drug capable of curing a disease. In 1950, a prestigious pharmacologist stated: "There are a dozen effective drugs, the rest are the result of sick people fear and the interests of the pharmaceutical industry".

Over the past decades, we have witnessed an inclination of the pendulum of medicine towards scientific and technological aspects, thus leaving aside its humanitarian aspect, another pillar of our profession. This led to a gradual loss of altruism, empathy, humility and also non-acceptance of uncertainty, which resulted in a false and disastrous belief that scientific knowledge was enough to conduct an appropriate medical practice. The most common and damaging consequence of this assumption is probably that physicians mistakenly believe that the healing process depends only on biological knowledge and technology. However, the one with more scientific knowledge is not usually the best physician. As science continues advancing steadily, it seems good physicians are becoming a rarity.

Traditional medical education models reinforce the concept of infallibility: physicians are not supposed to make mistakes. However, we do not get trained, either at the university or during our formative years, to cultivate a critical attitude that allows us to face mistakes.

There is no doubt that the "aura" of infallibility in medical practice is false because, as all human beings, we will inevitably make mistakes, no matter what our skills are.

These features have resulted in many physicians being unaware of their ample ignorance and incapable of tolerating uncertainty.

Stuart Firestein, a Professor of Neuroscience and Chair of the Department of Biological Sciences at Columbia University, addressed ignorance in a very original manner. He used to teach a highly formal and demanding course called "Cellular and Molecular Neuroscience", which lasted several months. Once, at the end of the course, he realized that many of his students thought that they "knew" all about neuroscience and even assumed that scientific knowledge increased by accumulating new facts. This is a misconception because knowledge basically increases by identifying errors and letting ignorance grow, and these require the elimination of old knowledge.

After this, Firestein decided to develop a new course on ignorance and started having special guest scientists speak about what they did not know, i.e., to discuss the importance of ignorance in the field of science. ${ }^{1}$ Such fascinating experience turned into a recently published book. ${ }^{2}$

This example helps us elucidate the reasons why, in medical practice, we fail to cultivate a critical attitude and humility -both essential to embrace uncertainty and recognize what we do not know. In order to try and reach knowledge and avoid potential errors, it is fundamental to accept and tolerate uncertainty given that, when dealing with complex situations, it will allow us to reflect on the most adequate options available before making a decision.

Some phrases represent several critical reflections about knowledge. An anonymous Italian proverb states: "Chi sa che non sa, sa. Chi sa che sa, non sa". ("He who knows he does not know, knows. He who knows he knows, does not").

Many physicians have described their own experience in medical practice. Here I will quote only two.

Bill Rogers, a famous American clinician, left us a wise reflection: "I do not worry about all that I do not know, my problem are the things I think I know". Also Murray Enkin, M.D., Professor Emeritus of Obstetrics, used to tell his medicine students on the first day of his course: 
"Half of everything I am going to say here is very likely wrong. The problem is I do not know which half". ${ }^{3}$

Traditionally, medicine was learnt at the side of patients and following the example of teachers; this was and still is a good and necessary approach, although it should be noted that at present there are not as many teachers. Changes have gradually led us to rely on technology because it allows us to access large amounts of information, although we should consider that most of it is irrelevant and unnecessary to be a good physician.

A risk would be that physicians who are still undergoing training and have access to plenty information believe that they know a lot, but it is quite the opposite.

It is necessary to develop a critical spirit that will make us be highly skeptical of the new concepts introduced as an undeniable truth. Thus, we will be able to make adequate decisions and know what to do, but especially what we should not do, because "not everything that can be done, should be done".

It is worth noting that, in the field of science, bedazzlement for the new is short-lived; what is true today will not hold true tomorrow.

I would like to briefly refer to physicians' thought process when it comes to making decisions and an adequate clinical judgment. During these turning points, thinking usually takes the wrong path and does not let us recognize that dazzling technological and scientific advances take place in situations of uncertainty and, therefore, information deceives the thinking process and clouds clinical judgment. ${ }^{4}$ Likewise, drifting thoughts are influenced by a highly widespread belief that medicine is only a science, which undoubtedly does not represent reality and does not do justice to what it really is or what it should ideally be. Kathryn Montgomery, Ph.D., left us an excellent reflection on this matter: "The complex social enterprise embodied by medicine is far away from the naïve visions of biological science still mistakenly surviving in the minds of many of its advocates, although it is not a true reflection of medicine, which is ruled by contingency". ${ }^{4}$

Finally, I would like to highlight a concept that supports our commitment to improving medical practice. It is necessary to understand that medical education is both intellectual and moral; so we should prepare both medicine students and physicians to live with uncertainty, paradox and contradiction.

Jose M. Ceriani Cernadas, M.D. Editor

http:/ /dx.doi.org/10.5546/aap.2016.eng.98

1. http:/ / ilevolucionista.blogspot.com.es/2014/01/laignorancia-y-la-ciencia.html.

2. Firestein S. Ignorance: How it drives Science. Oxford: Oxford University Press, 2012.

3. Enkin MW. The seven stages of the ignorance. Birth 2008; 35(3):169-70

4. Montgomery K. How doctors think: clinical judgment and the practice of medicine. Oxford: Oxford University Press, 2006. 